\title{
Extracorporeal shock wave therapy in the treatment of patellar tendinopathy: the ASSERT database
}

\author{
Gayle Maffulli1 \\ Johnny Padulo ${ }^{2,3}$ \\ Enzo luliano ${ }^{2}$ \\ John Furia ${ }^{4}$ \\ Jan Rompe ${ }^{5}$ \\ Nicola Maffulli6,7
}

1 Wholelife Clinics, London, UK

2 University eCampus, Novedrate, Italy

3 Faculty of Kinesiology, University of Split, Split, Croatia

4 SUN Orthopedics of Evangelical Community Hospital, Lewisburg, USA

${ }^{5}$ OrthoTrauma Evaluation Institute, Mainz, Germany

${ }^{6}$ Department of Musculoskeletal Disorders, Faculty of Medicine and Surgery, University of Salerno,

Salerno, Italy

${ }^{7}$ Centre for Sports and Exercise Medicine, Barts and the London School of Medicine and Dentistry, Mile End Hospital, London, UK

Corresponding author:

Nicola Maffulli

Department of Musculoskeletal Disorders

School of Medicine and Surgery

University of Salerno,

Mary University of London

Barts and the London School of Medicine and Dentistry

Centre for Sports and Exercise Medicine

Mile End Hospital 275 Bancroft Road

E1 4DG, London, England, UK

Tel.: +447989358279

E-mail:n.maffulli@qmul.ac.uk

\section{Summary}

Introduction: This study aimed to determinate the effectiveness of extracorporeal shock wave therapy (ESWT) for patients suffering from patellar tendinopathy (PT) in both the short and long term. Methods: The participants of this study were recruited by different clinicians of the National Health Service (NHS) and private sector centres in the United Kingdom. Data were collected in a web-based database (Assessment of the Effectiveness of Extracorporeal Shock Wave Therapy (ESWT) for soft Tissue Injuries (ASSERT)). The 49 participants (mean age $39.26 \pm 11.70$ y) were treated using a standardized ESWT protocol. At baseline and again at 3, 6, 12 and 24 months following ESWT treatment, the participants were evaluated with the Visual Analogue Scale (VAS) for pain perception, the VISA-P scale for functional limitation assessment, and the 6 scores of the EuroQol-5D questionnaire (EQ-5D) for quality of life.

Results: There was a significant improvement over time in 4 of the 8 analysed scores (all with at least $p=0.0001$ ). The scores that significantly improved were VAS, VISA-P, and 2 scores of EQ-5D (Pain/Discomfort and Usual Activities).

Conclusion: ESWT showed beneficial effects on PT over a 24-month follow-up period.

Level of evidence: IV.

KEY WORDS: extracorporeal shock wave therapy, longitudinal study, patellar tendinopathy.

\section{Introduction}

Patellar tendinopathy (PT), often referred to a "jumper's knee", is an injury associated with sports which involve jumping or running and frequent change of direction ${ }^{1}$. PT tends to affect both recreational and elite athletes. The prevalence of PT is estimated to range from $14.2 \%$ in the general population, to around $44.6 \%$ in elite volleyball players ${ }^{2}$ and as little $2.5 \%$ in soccer players ${ }^{3}$. The diagnosis of chronic patellar tendinopathy is largely clinical, and the extent of improvement can be quantified using the VISA-P ${ }^{4}$. Many conservative treatments are used, with variable success rates ${ }^{3-6}$. For those patients in whom conservative management has not been effective $^{7}$, extracorporeal shock wave therapy (ESWT) can be effective 6 .

ESWT is being used in the management of PT, but not all trials have yielded positive results, and some of the therapeutic effects of ESWT require further investigation. Studies compared radial and focused shockwave therapy for PT with varying success ${ }^{8,} 9$. Researchers in the field have called for additional investigations, using homogenous interventions, identical outcome assessment, comparable participants, and comparable follow-up evaluations ${ }^{10}$. For patellar tendinopathy, there is no NICE (National Institute for Health and Care Excellence) guidance, but ESWT in patellar tendinopathy "seems to be a safe and 
promising treatment"11 and therefore, as for other conditions for which ESWT is being used, special arrangements should be made to audit practice. The Assessment of Effectiveness of ESWT for Soft Tissue Injuries (ASSERT) is one such database, the aim of which is to determine the effectiveness of ESWT in patients suffering from selected soft tissue injuries in both the short and long term ${ }^{12}$.

This study evaluated the effectiveness of ESWT in patients with chronic PT enrolled in ASSERT over 24 months considering different aspects, namely the reduction of the clinical severity of symptoms, the relief of pain, and the improvement of the quality of life.

\section{Materials and methods}

The ASSERT database was used to collect information on the effectiveness of ESWT across the United Kingdom. The ESWT machines were standardised and a standardised treatment protocol, together with standardised baseline measurements and outcome measures and time points in centres across the United Kingdom, were adopted to aid validity ${ }^{12}$.

\section{Recruitment}

Participants were recruited from both the National Health Service (NHS) and private sector centres in the United Kingdom. Clinicians recruited participants presenting with insertional plantar fasciitis, and for whom ESWT was indicated as the treatment choice.

\section{Participants}

Participants were included if they were over the age of 18 , had a diagnosis of PT confirmed by the recruiting clinician; undergone a course of conservative therapy which had not been effective in relieving symptoms; been recommended to receive ESWT at one of the recruiting centres; not been diagnosed with inflammatory arthropathy; and demonstrated the ability to give informed consent.

A total of 51 participants (44 males; 7 females) were enrolled and 49 participants (43 males and 6 females) met all the inclusion criteria and were considered for analysis (Tab. I).

This study has been designed and conducted in accordance with the principles of the Declaration of Helsinki and it has been approved by the Local Ethics Committee (11/LO/0253). A written informed consent was obtained by each participant ${ }^{13}$.

\section{Use of ESWT machine}

Standardisation of the machine and the process of administration of ESWT had been agreed to ensure consistency, reproducibility and generalisability of the results. All clinicians using the Swiss DolorClast device (Electro Medical Systems SA, Nyon, Switzerland) and Stortz devices (Stortz Medical AG, Tägerwilen, Switzerland) received training and certification to ensure adherence to the protocol. All clinicians followed a standardised method of administration of ESWT ${ }^{14}$. This included delivering an initial 500 "warm-up" impulses at a low air pressure (1.5 bar of air pressure). This reduces the pain which patients experience during treatment. Based on patient feedback, the clinician then increased the air pressure to 2.5 bar or above. The total dose of impulses remained constant at 2500 per session, with one session a week for three planned consecutive weeks, with a maximum gap between two consecutive treatments of two weeks.

\section{Database}

The ASSERT database is a web based system (www.assert.org.uk) from which the clinician received a study number for each participant ${ }^{12}$. Only unidentifiable information with the patients' study number was entered into the database. Sensitive data are held on secure servers. Following informed consent, the clinician recorded the following information: (1) Diagnosis: this was formulated on clinical grounds and some clinicians also used imaging to confirm the diagnosis; (2) Area treated/condition presented with; (3) Date of presentation of symptoms; (4) Date of treatment of ESWT; (5) Code for clinicians centre; (6) Centre where treatment was administered; (7) Previous treatments prior to consultation; (8) Side treated; (9) Dates when ESWT was administered; (10) Baseline scores recorded: EuroQol questionnaire scores (EQ5D) ${ }^{15}$, Visual Analogue Scale for pain (VAS) ${ }^{16}$, and VISA-P scale4; (11) Follow-up scores at 3, 6, 12 and 24 months post treatment; (12) Satisfaction: rated poor, satisfactory, good or excellent; (13) Time to effective treatment; (14) Recurrence of the condition; (15) Complications; and (16) Adverse events.

\section{Baseline and follow-up assessments}

After having obtained written informed consent, the treating clinician undertook baseline assessments. The follow-up assessments were instead performed after 3, 6, 12 and 24 months' post treatment. The co-

Table I. Sample of participants.

\begin{tabular}{llll}
\hline & $\mathbf{n}$ & Age $(\mathbf{y})$ & $\begin{array}{l}\text { Number of previous } \\
\text { treatments }\end{array}$ \\
\hline Participants enrolled & 51 (44 males and 7 females) & $39.32 \pm 11.57$ & $1.71 \pm 1.02$ \\
Participants considered for the analyses & 49 (43 males and 6 females) & $39.26 \pm 11.70$ & $1,68 \pm 0.97$ \\
\hline
\end{tabular}


ordinators of ASSERT undertook all follow-up assessments via email, telephone or post.

\section{Outcome assessment}

The EQ-5D ${ }^{15}$ and VAS for pain ${ }^{16}$ were completed alongside the VISA-P4.

The EQ-5D is a standardised measure of health status developed by the EuroQol Group to provide a simple, generic measure of health for clinical and economic appraisal. For the present study, the version 3L (EQ-5D-3L) was used. This is a simple questionnaire composed of 5 items with a 3-point scale answer for each item, and designed for completion by the person being treated. Each one of the 5 items respectively investigates 5 dimensions of the quality of life, namely (1) mobility, (2) self-care, (3) usual activities, (4) pain/discomfort, and (5) anxiety/depression. A score from 1 (best score) to 3 (worst score) is assigned for each dimension. The EQ-5D also includes a scale, named EQ-5D Thermometer Scale, that allows obtaining a global score to generally describe the quality of life of the patient. It consists in a vertical line, $100 \mathrm{~mm}$ in length, anchored by 2 word descriptors at each end, which are "the worst health you can imagine" and "the best health you can imagine". Patients are asked to mark on the line the point which they feel represents their perception of their current health status. The score ranges from 0 (worst health status) to 100 (best health status), and it is computed by measuring the distance (in $\mathrm{mm}$ ) between the end of the line marked with "the worst health you can imagine" and the mark on the line indicated by the patient.

The VAS for pain (or Visual Analogue Scale for pain) is very similar to the EQ-5D Thermometer Scale, but it focuses only on the pain perceived by the patient, not on the overall quality of life. It consists in a horizontal line, $100 \mathrm{~mm}$ in length, which asks the patients "How severe is your pain today?". The line is anchored by 2 word descriptors at each end, which are "no pain" and "very severe pain". Also in this case, patient mark on the line the point which they feel represents their current perception of their pain intensity. The score, from 0 (no pain) to 100 (very severe pain), is computed as the measurement of the distance (in $\mathrm{mm}$ ) between the end of the line marked with "no pain" and the point on the line indicated by the patient.

The VISA-P scale (Victorian Institute of Sport Assessment scale for Patellar tendinopathy) is a brief questionnaire assessing the symptoms, the limitation to play sport due to PT. Six of the eight questions are scored on a visual analogue scale from 0-10 with 10 representing optimal health. The global VISA-P score ranges from 100 (asymptomatic, fully performing individual) to 0 points.

\section{Statistical analysis}

Linear Mixed Model analysis (LMM) with maximum likelihood method was performed in order to evaluate the significant effects over time produced by ESWT in the treatment of the PT. To perform the LMM analysis, the Time factor (fixed factor: T0 vs T3 vs T6 vs T12 vs T24) was used to investigate differences over time. The VAS and the VISA-P scores, as well as the 6 scores of the EQ-5D were considered as dependent variables for the analysis. If two or more of the followup datasets were missing the patient was excluded.

Due to the multiple dependent variables, the Bonferroni correction was used adjust the $p$-value. The Bonferroni correction indicates an adjusted $p$-value $<0.006$ for significance.

When a significant effect over time was detected, Bonferroni post-hoc analysis (adjusted for multiple comparison) was used to perform comparisons in pair among the different time of assessments.

All the analyses were performed with the statistical software SPSS 20 (IBM Corporation, Chicago, IL, USA).

\section{Results}

There was a significant reduction over time in the VAS score $\left(F_{4,69}=14.343 ; p<0.0001\right)$.

Similarly, also the VISA-P scores significantly improved over time $\left(F_{4,67}=8.551 ; p<0.0001\right)$.

Concerning the EQ-5D questionnaire domains, the EQ-5D Anxiety/Depression $\left(F_{4,46}=0.784 ; p=0.541\right)$, in the EQ-5D Mobility score $\left(F_{4,68}=0.963 ; p=0.433\right)$, in the EQ-5D Self-Care $\left(F_{4,55}=0.928 ; p=0.455\right)$, and in the EQ-5D Thermometer Scale $\left(F_{4,53}=6.821\right.$; $p=0.823)$, whereas, a significant reduction over time were found in the EQ-5D Pain/Discomfort score $\left(F_{4,77}=12.494 ; p<0.0001\right)$, and in the EQ-5D Usual Activities score $\left(F_{4,74}=6.579 ; p=0.0001\right)$. In order to have more clarity, all the data are reported as Means \pm SD in Table II with the results of the post-hoc analysis.

\section{Discussion}

ESWT produced a significant beneficial effect in the management of PT in 4 of the 8 analysed variables. In particular, the results indicated that VAS scores were significantly positively affected after only 3 months, with no successive additional ameliorations during the 24 months of observation. On the contrary, the 2 significant scores of the EQ-5D (namely Pain/Discomfort and Usual Activities scores) needed 6 months to achieve a significant amelioration. The VISA-P scores seem to need more time to improve (12 months), but further amelioration was obtained after 2 years compared with T3 and T6.

ESWT produced significant positive effects in reducing pain and function, and improving the ability of the patients to manage everyday life as indicated by the significant amelioration of VAS and VISA-P score respectively. Also, the quality of life was significantly enhanced after ESWT intervention for pain and discomfort and usual activities. The Anxiety/Depression, 
Mobility and Self-Care dimensions' scores were not changed significantly. However, the baseline scores of these three dimensions (Tab. II) were substantially low, and they remained low for the whole duration of the follow-up. Consequently, the non-significant modification of these three scores was probably attributable to a low impact of PT on these three dimensions since the baseline assessment.

Another clinically important finding concerns the time necessary to obtain significant benefits on quality of life, function and pain relief. In fact, there was a significant improvement three months after the last session of ESWT in VAS only. The EQ-5D Pain/Discomfort, and EQ-5D Usual Activities took 6 months for a significant amelioration in comparison to the baseline score. The VISA-P took 12 months for a significant amelioration in comparison with the baseline score, and the score improved further by 24 months. Given these results, ESWT can be considered a valid and effective method for the treatment of PT.

The results of the present study are in accordance with recent reviews performed in $2012^{17}$ and in $2015^{7}$, confirming that ESWT is safe and effective in the non-surgical management of PT. There have been a number of studies reporting favourable results in athletes using ESWT for PT with success rates varying from 73.5 to $87.5 \% 5,6,11,18-23$.

Furia et al. ${ }^{24}$ demonstrated a significant improvement in pain and function with a single session of low energy radial pressure waves and Crupnik reported that 3 weekly sessions of radial shockwave therapy alongside eccentric exercises resulted in $76 \%$ good or excellent results ${ }^{25}$. Conversely, two studies reported poor results when using ESWT for $\mathrm{PT}^{26,27}$. However, Zwerver et al. ${ }^{26}$ treated high performance athletes during competition, and Vertano et al. ${ }^{27}$ used a protocol which had not been previously validated of one ESWT session every 48-72 hours. These anomalies may explain the negative results. Of the studies which reported favourable results only two reported significant improvements using ESWT for $\mathrm{PT}^{8,23}$. However, the significance of these results has been questioned $^{8}$ since the difference in VISA-P scores did not reach the value for the minimal clinical important difference (MCID) (15 points) ${ }^{28,29}$. The present study found not only statistical significance but also the MCID for the VISA-P at 12 and 24 months. Therefore, it is clinically effective, but it takes 12 to 24 months to get the true clinical effectiveness for PT.

The literature identified the need for systems to be in place to audit the treatment in regards to diagnostic classification criteria, outcomes, baseline measures and aspects of treatment applied ${ }^{10}$. In this respect, the ASSERT database plays an important role. In fact, ASSERT aimed to collect high quality and relevant data about the effectiveness of ESWT in patients with PT in a pragmatic and systematic manner to improve the quality of outcomes and ensure the quality and cost effectiveness of ESWT. ASSERT can monitor the outcomes achieved by practitioners and identify where these fall below an expected performance to inform best practice and additional training requirements.

The present evidence confirms in a pragmatic setting that ESWT is an effective therapy for PT, and builds upon previous research which clearly indicates ESWT as beneficial for the management of $\mathrm{PT}^{5-7,11,17,20-}$ $22,24,25$. No analysis is perfect, and we acknowledge that many other variables such as the amount of energy employed, high vs low intensity shock wave treatment, the methods of localization of the shock waves, the number of shocks, and the number of sessions must also be considered when evaluating the efficacy of ESWT. Also, we point out that the protocol used to administer extracorporeal shock wave treatment in ASSERT is based on the protocol as indicated by the ISMST, which is based upon the good results in safety and efficacy in clinical trials of all levels of evidence 29 . Nevertheless, we acknowledge that more high-quality and well-conducted studies are necessary. A database such as ASSERT could be a valid method for the systematic collection of a large amount of data and for the standardization of procedures to obtain strong evidences in this field.

Concerning the limitations, this study is not a randomised controlled trial. However, Level I studies have been conducted in the present field, and have shown that ESWT, when administered according to protocols as approved by the ISMST ${ }^{30}$, is safe and effective in the management of the condition at hand. For patellar tendinopathy, there is no NICE guidance, but NICE has identified that ESWT in patellar tendinopathy "seems to be" a safe and promising treatment ${ }^{11}$. Therefore, as for other conditions for which ESWT is being used, special arrangements should be made to audit practice. The ASSERT protocol is NICE compliant, and satisfies the requirements set out by NICE. Many different clinicians were involved in the treatment, after appropriate certified training and standardisation of the protocol, and the effects of treatment were evaluated by independent individuals. This increases the generalizability of the present findings, and, in this respect, should be considered a major strength of the present study. Also, all patients previously had failed a variety of conservative management means, and this was a major criterion to be recruited in the present study ${ }^{7}$.

In conclusion, when administered in a standardised fashion to an unselected population of patients suffering from patellar tendinopathy, ESWT therapy is safe and effective in alleviating symptoms for up to 24 months.

\section{Compliance with ethical standards}

\section{Conflict of interest}

All Authors declare no conflict of interest.

\section{Funding}

The ASSERT database has been developed and established through funds provided by Industry (Spectrum Technology UK) and ESPRC grants. 
Table II. Results relative to the effects over time with the post-hoc analyses outputs.

\begin{tabular}{|c|c|c|c|c|c|c|c|c|}
\hline \multirow[t]{2}{*}{ Tests } & & \multirow{2}{*}{$\begin{array}{l}\text { TO } \\
\text { Means } \\
\text { SD (N) }\end{array}$} & \multirow{2}{*}{$\begin{array}{c}\text { T3 } \\
\pm \text { Means } \\
\text { SD }(\mathrm{N})\end{array}$} & \multirow{2}{*}{$\begin{array}{c}\text { T6 } \\
\text { Means } \\
\text { SD (N) }\end{array}$} & \multirow{2}{*}{$\begin{array}{c}\text { T12 } \\
\pm \text { Means } \\
\text { SD (N) }\end{array}$} & \multirow{2}{*}{$\begin{array}{c}\text { T24 } \\
\pm \text { Means } \\
\text { SD (N) }\end{array}$} & \multirow{2}{*}{$\begin{array}{l}\text { Overall } \\
\text { significance } \\
\pm \text { in time }\end{array}$} & \multirow{2}{*}{$\begin{array}{l}\text { Comparisons in } \\
\text { pair - } \\
\text { significance }\end{array}$} \\
\hline & & & & & & & & \\
\hline \multirow[t]{2}{*}{ VAS } & Scores & $\begin{array}{l}52.83 \pm \\
20.86(46)\end{array}$ & $\begin{array}{l}33.79 \pm \\
25.29(19)\end{array}$ & $\begin{array}{l}24.74 \pm \\
22.36(19)\end{array}$ & $\begin{array}{l}20.93 \pm \\
24.58(14)\end{array}$ & $\begin{array}{l}21.88 \pm \\
25.42(8)\end{array}$ & $p<0.0001$ & $\begin{array}{l}\text { T0 vs T3, T6, } \\
\text { T12, T24 }\end{array}$ \\
\hline & $\begin{array}{l}\text { Difference } \\
\text { with } \\
\text { baseline } \\
\text { score }\end{array}$ & - & -19.04 & -28.09 & -31.90 & -30.95 & & \\
\hline \multirow[t]{2}{*}{ VISA-P } & Scores & $\begin{array}{l}49.33 \pm \\
18.7(40)\end{array}$ & $\begin{array}{l}52.83 \pm \\
21.46(18) \\
\end{array}$ & $\begin{array}{l}61.11 \pm \\
22.66(19) \\
\end{array}$ & $\begin{array}{l}66.64 \pm \\
26.5(14) \\
\end{array}$ & $\begin{array}{l}75.63 \pm \\
21.90(8)\end{array}$ & $p<0.0001$ & $\begin{array}{l}\text { T0 vs T12, T24 } \\
\text { T3 vs T24 }\end{array}$ \\
\hline & $\begin{array}{l}\text { Difference } \\
\text { with } \\
\text { baseline } \\
\text { score }\end{array}$ & - & 3.51 & 11.78 & 17.32 & 26.30 & & $\mathrm{~T} 6$ vs T24 \\
\hline \multirow[t]{2}{*}{$\begin{array}{l}\text { EQ-5D } \\
\text { Anxiety/Depression }\end{array}$} & Scores & $\begin{array}{l}1.14 \pm \\
0.35(43)\end{array}$ & $\begin{array}{l}1.11 \pm \\
0.32(18)\end{array}$ & $\begin{array}{l}1.11 \pm \\
0.32(19) \\
\end{array}$ & $\begin{array}{l}1.00 \pm \\
0.00(14)\end{array}$ & $\begin{array}{l}1.00 \pm \\
0.00(8)\end{array}$ & $\begin{array}{l}\text { Not } \\
\text { significant }\end{array}$ & - \\
\hline & $\begin{array}{l}\text { Difference } \\
\text { with } \\
\text { baseline } \\
\text { score }\end{array}$ & - & -0.03 & -0.03 & -0.14 & -0.14 & & \\
\hline \multirow[t]{2}{*}{ EQ-5D Mobility } & Scores & $\begin{array}{l}1.26 \pm \\
0.44(43)\end{array}$ & $\begin{array}{l}1.33 \pm \\
0.49(18)\end{array}$ & $\begin{array}{l}1.21 \pm \\
0.42(19)\end{array}$ & $\begin{array}{l}1.14 \pm \\
0.36(14)\end{array}$ & $\begin{array}{l}1.13 \pm \\
0.35(8)\end{array}$ & $\begin{array}{l}\text { Not } \\
\text { significant }\end{array}$ & - \\
\hline & $\begin{array}{l}\text { Difference } \\
\text { with } \\
\text { baseline } \\
\text { score }\end{array}$ & - & 0.08 & -0.05 & -0.11 & -0.13 & & \\
\hline \multirow[t]{2}{*}{$\begin{array}{l}\text { EQ-5D } \\
\text { Pain/Discomfort }\end{array}$} & Scores & $\begin{array}{l}1.98 \pm \\
0.27(43) \\
\end{array}$ & $\begin{array}{l}1.72 \pm \\
0.46(18) \\
\end{array}$ & $\begin{array}{l}1.58 \pm \\
0.51(19) \\
\end{array}$ & $\begin{array}{l}1.43 \pm \\
0.51(14) \\
\end{array}$ & $\begin{array}{l}1.25 \pm \\
0.46(8)\end{array}$ & $p<0.0001$ & $\begin{array}{l}\text { T0 vs T6, T12, } \\
\text { T24 }\end{array}$ \\
\hline & $\begin{array}{l}\text { Difference } \\
\text { with } \\
\text { baseline } \\
\text { score }\end{array}$ & - & -0.25 & -0.40 & -0.55 & -0.73 & & T3 vs T24 \\
\hline \multirow[t]{2}{*}{$\begin{array}{l}\text { EQ-5D Usual } \\
\text { Activities }\end{array}$} & Scores & $\begin{array}{l}1.72 \pm \\
0.50(43) \\
\end{array}$ & $\begin{array}{l}1.39 \pm \\
0.50(18)\end{array}$ & $\begin{array}{l}1.37 \pm \\
0.50(19) \\
\end{array}$ & $\begin{array}{l}1.14 \pm \\
0.36(14) \\
\end{array}$ & $\begin{array}{l}1.25 \pm \\
0.46(8) \\
\end{array}$ & $p=0.0001$ & $\begin{array}{l}\text { T0 vs T6, T12, } \\
\text { T24 }\end{array}$ \\
\hline & $\begin{array}{l}\text { Difference } \\
\text { with } \\
\text { baseline } \\
\text { score }\end{array}$ & - & -0.33 & -0.35 & -0.58 & -0.47 & & \\
\hline \multirow[t]{2}{*}{ EQ-5D Self-Care } & Scores & $\begin{array}{l}1.07 \pm \\
0.26(43) \\
\end{array}$ & $\begin{array}{l}1.00 \pm \\
0.00(18)\end{array}$ & $\begin{array}{l}1.05 \pm \\
0.23(19) \\
\end{array}$ & $\begin{array}{l}1.07 \pm \\
0.27(14) \\
\end{array}$ & $\begin{array}{l}1.00 \pm \\
0.00(8)\end{array}$ & $\begin{array}{l}\text { Not } \\
\text { significant }\end{array}$ & - \\
\hline & $\begin{array}{l}\text { Difference } \\
\text { with } \\
\text { baseline } \\
\text { score }\end{array}$ & - & -0.07 & -0.02 & 0.00 & -0.07 & & \\
\hline \multirow[t]{2}{*}{$\begin{array}{l}\text { EQ-5D } \\
\text { Thermometer Sc. }\end{array}$} & Scores & $\begin{array}{l}71.30 \pm \\
25.63(43)\end{array}$ & $\begin{array}{l}78.33 \pm \\
16.66(18)\end{array}$ & $\begin{array}{l}77.47 \pm \\
12.53(19)\end{array}$ & $\begin{array}{l}81.93 \pm \\
8.00(14)\end{array}$ & $\begin{array}{l}79.00 \pm \\
15.48(8)\end{array}$ & $\begin{array}{l}\text { Not } \\
\text { significant }\end{array}$ & - \\
\hline & $\begin{array}{l}\text { Difference } \\
\text { with } \\
\text { baseline } \\
\text { score }\end{array}$ & - & 7.03 & 6.17 & 10.63 & 7.70 & & \\
\hline
\end{tabular}

$p$-value for significance after Bonferroni correction is $<0.006$. 


\section{Acknowledgements}

We thank Mr Jim Westwood and Mr Chris Schiel from Spectrum Technology for their support. Mr Nathan Bentley of twotwentyseven London Ltd - a creative digital agency developed the ASSERT platform following the direction of Professor Nicola Maffulli and Mrs Gayle Maffulli.

We thank all the clinicians recruiting participants onto the ASSERT database and the participants of ASSERT. Professor Nicola Maffulli developed the concept of ASSERT.

\section{Ethical approval}

All procedures performed in this study involving human participants were in accordance with the ethical standards of the institutional and/or national research committee and with the 1964 Helsinki Declaration and its later amendments or comparable ethical standards.

\section{Informed consent}

Informed consent was obtained from all individual participants included in the study.

\section{References}

1. Blazina ME, Kerlan RK, Jobe FW, Carter VS, Carlson GJ. Jumper's knee. Orthop Clin North Am. 1973;4:665-678.

2. Lian OB, Engebretsen L, Bahr R. Prevalence of jumper's knee among elite athletes from different sports: a cross-sectional study. Am J Sports Med. 2005;33:561-567.

3. Zwerver J, Bredeweg SW, Van den Akker-Scheek L. Prevalence of jumper's knee among nonelite athletes from different sports: a cross-sectional survey. Am J Sports Med. 2011;39: 1984-1988.

4. Visentini PJ, Khan KM, Cook JL, Kiss ZS, Harcourt PR, Wark JD. The VISA score: an index of severity of symptoms in patient's with jumper's knee (patellar tendinosis). Victorian Institute of Sport Tendon Study Group. J Sci Med Sport. 1998 1:22-28.

5. Vulpiani MC, Vetrano M, Savoia V, Di Pangrazio E, Trischitta D, Ferretti A. Jumper's knee treatment with extracorporeal shock wave therapy therapy; a long-term follow-up observational study. J. Sports Med. Phys. Fit. 2007;46:323-328.

6. Wang CJ, Ko JY, Chan YS, Weng, Hsu SI. Extracorporeal shockwave for chronic patellar tendinopathy. Am J Sports Med. 2007;35:972-978.

7. Leal C, Ramon S, Furia J, Fernandez A, Romero L, Hernandez-Sierra L. Current concepts of shockwave therapy in chronic patellar tendinopathy. Int J Surg. 2015;24:160-164.

8. Van der Worp H, Zwerver J, Hamstra M, Van den AkkerScheek, Diercks RI. No difference in effectiveness between focused and radial shockwave therapy for treating patellar tendinopathy: a randomized controlled trial. Knee Surg Sports Traumatol Arthrosc. 2014;22:2026-2032.

9. Serrano E, Criado JC. ESWT therapy in patellar tendinopathy comparison of 2 protocols, in: Transactions of the $17^{\text {th }}$ International Congress of the ISMST. Jun 2014:2014.

10. Korakakis V, Whitely R, Tzavara A, Malliaropoulos N. The effectiveness of extracorporeal shockwave therapy in common lower limb conditions: a systematic review including quantification of patient-related pain reduction. Br J Sports Med. 2017:1-22.

11. Van Leeuwen MT, Zwerver J, van den Akker-Scheek I. Extracorporeal shockwave therapy for patellar tendinopathy: a review of the literature. Br J Sports Med. 2009 Mar;43(3):163168.

12. Maffulli G, Hemmings S, Maffulli N. Assessment of the Effectiveness of Extracorporeal Shock Wave Therapy (ESWT) For Soft Tissue Injuries (ASSERT): An Online Database Protocol. Transl Med @ UniSa. 2014;10:46-51.

13. Padulo J, Oliva F, Frizziero A, Maffulli N. Muscles, Ligaments and Tendons Journal - Basic principles and recommendations in clinical and field science research: 2016 update. MLTJ. 2016;6(1):1-5.

14. Gerdesmeyer L, Wagenpfeil S, Haake M, Maier M, Loew M, Wörtler K, et al. Extracorporeal Shock Wave Therapy for the Treatment of Chronic Calcifying Tendonitis of the Rotator Cuff: a randomized controlled trial. JAMA. 2003;290:2573-2580.

15. EuroQol-Group. EuroQol: a new facility for the measurement of health related quality of life. Health Policy. 1990;16:199-208.

16. Scott J, Huskisson EC. Graphic representation of pain. Pain. 1976;2:175-184.

17. Wang CJ. Extracorporeal Shockwave therapy in musculoskeletal disorders (Review). J Orthop Surg Research. 2012;7:11;1-8.

18. Vara F, Garzon N, Ortega N. Treatment of the patellar tendinitis with local application of extracorporeal shock waves. Abstract from the $4^{\text {th }}$ Congress of the International Society for Musculoskeletal Shock Wave Therapy. Naples, 2000.

19. Moretti B, Notarnicola A, Maggio G, Moretti L, Pascone M, Tafuri S, Patella V. A volleyball player with bilateral knee osteochondritis dissecans treated with extracorporeal shock wave therapy. Musculoskeletal Surgery. 2009;93(1):37-41.

20. Zwerver J, Dekker F, Pepping GJ. Patient guided Piezo-electric Extracorporeal Shockwave Therapy as treatment for chronic severe patellar tendinopathy: a pilot study. J Back Musculoskeletal Rehab. 2010;23(3):111-115.

21. Hsu RW, Hsu WH, Tai CL, Lee KF. Effect of shock-wave therapy on patellar tendinopathy in a rabbit model. J Orthop Res. 2004;22(1):221-227.

22. Peers KH, Lysens RJ, Brys P, Bellemans J. Cross-sectional outcome analysis of athletes with chronic patellar tendinopathy treated surgically and by extracorporeal shock wave therapy. Clin J Sport Med. 2003;13(2):79-83.

23. Thijs KM, Zwerver J, Backx FJ et al. Effectiveness of Shockwave Treatment Combined with Eccentric training for patellar tendinopathy in professional Athletes. Am J Sports Med. 2017;27:89-96

24. Furia JP, Rompe JD, Cacchio A, Del Buono A, Maffulli N. A single application of low-energy radial extracorporeal shock wave therapy is effective for the management of chronic patellar tendinopathy. Knee Surg Sports Traumatol Arthrosc. 2013;21 346-350.

25. Crupnik J. Eccentric loading plus radial shockwave therapy in the treatment of chronic patellar tendinopathy, in: Transactions of the $12^{\text {th }}$ International Congress of the ISMST. Jun 2009.

26. Zwerver J, Van Den Akker-Scheek I, Hartgens F, Van De Worp H, Verhagen E, Diercks R. No effect of shockwave therapy in jumping athletes with patellar tendinopathy: a randomised controlled trial in: Transactions of the $13^{\text {th }}$ International Congress of the ISMST. Jun 2010:2010.

27. Vetrano M, Castorina A, Vulpiani MC, Baldini R, Pavan A, Ferretti A. Platelet-rich plasma versus focused shock waves in the treatment of jumper's knee in athletes. Am J Sports Med. 2013:41:795-803.

28. Wageck BB, de Noronha M, Lopes AD, et al. Cross-cultural adaptation and measurement properties of the Brazilian Por- 
tuguese Version of the Victorian Institute of Sport Assessment- Patella (VISA-P) Scale. J Orthop Sports Phys Ther. 2013;43:163-171.

29. Hermandez-Sachez S, Hidalgo MD, Gomez A. Cross-cultural adaptation of VISA-P score for patellar tendinopathy in Spanish population. J Orthop Sports Phys Ther. 2011;41:581-591. 30. ISMST. https://www.shockwavetherapy.org. Accessed $28^{\text {th }}$ April 2018. 